\title{
Geoelectric structure estimated from magnetotelluric data from the Uttarakhand Himalaya, India
}

\author{
Rohit Miglani $^{1}$, M Shahrukh ${ }^{1}$, M Israil $^{1, *}$, Pravin K Gupta $^{1}$, S K Varshney ${ }^{2}$ \\ and Sokolova Elena ${ }^{3}$ \\ ${ }^{1}$ Indian Institute of Technology Roorkee, Roorkee 247 667, India. \\ ${ }^{2}$ Department of Science and Technology, New Mehrauli Road, New Delhi 110 016, India. \\ ${ }^{3}$ Institute of the Physics of the Earth, Russian Academy of Sciences, Moscow, Russia. \\ ${ }^{*}$ Corresponding author. e-mail: mohammad.israil@gmail.com
}

Geoelectric strike and resistivity structure of the crust have been estimated from 37 magnetotelluric (MT) data sites along a profile from Roorkee to Gangotri in Uttarakhand Himalaya. Impedance decomposition schemes based on Bahr's, Groom Bailey and Phase tensor were implemented in a MATLAB code for the average strike estimation. Geoelectric strike direction varies with period as well as in different lithotectonic units along the profile. In the period band from 1 to $100 \mathrm{~s}$ average geoelectric strike in the southern end of the profile (Indo-Gangetic Plains) is $\mathrm{N} 79^{\circ} \mathrm{W}$, which is slightly rotated to the north in the Lesser Himalayan region and becomes $\mathrm{N} 68^{\circ} \mathrm{W}$ whereas it is $\mathrm{N} 81^{\circ} \mathrm{W}$ in the Higher Himalayan region. However, average strike is stabilized to $\mathrm{N} 77^{\circ} \mathrm{W}$ for the entire profile in the long period band (100-1000 s). Geoelectrical structure of the crust has been obtained along the profile by 2D inversion of MT data. Major features of 2D resistivity model are: (i) southern part of the model is a low resistivity $(<50 \Omega \mathrm{m})$ zone at shallow depth $(5-7 \mathrm{~km})$ representing the loose sediments of the Indo-Gangetic Plains (IGP), whose thickness increases in the south; (ii) highly resistive $(>1000 \Omega \mathrm{m})$ layer below the IGP sediments is the basement rock, representing the resistivity of the top of the subducting Indian Plate; (iii) the Main Boundary Thrust (MBT) and the Main Central Thrust (MCT) zones can be seen in the electrical image. However, the Himalayan Frontal Thrust (HFT) could not be resolved and (iv) a low resistivity $(<10 \Omega \mathrm{m})$ feature in the MCT zone extending to the depth of $30 \mathrm{~km}$ is delineated. This low resistivity could be due to fluid-filled fractured rock matrix or partial melt zone. Hypocenters of many earthquakes are concentrated along the boundary of this low resistivity zone and relatively high resistivity blocks around it. The resulted model supports flat-ramp-flat geometry of the Main Himalayan Thrust along which the Indian Plate is subducting.

\section{Introduction}

The Himalaya is one of the youngest and highest mountain range, which originated from continental collision tectonics and underthrusting of the Indian Plate beneath the Eurasian Plate. Regional $\mathrm{N}-\mathrm{S}$ compression, resulting from horizontal movement of rock masses along the north dipping thrust planes, caused crustal shortening, horizontal extrusion, and lithospheric delamination (Le Fort 1975; Molnar 1990). In this process, leading upper brittle portion of the subducting Indian crust has been sliced and stacked up southwards to form the Himalayan mountain belt. The various regional thrust systems in the area, namely, the Main Central Thrust (MCT), the Main Boundary Thrust

Keywords. Magnetotelluric; Uttarakhnad Himalayan region; geoelectric strike; crustal structure. 
(MBT) and the Main Frontal Thrust (MFT) are the elements of this geodynamical process. Seeber et al. (1981) have postulated a gently dipping thrust (detachment surface) at the top of the Indian Plate under the Indo-Gangetic Plains along the upper surface of the subducting Indian lithosphere, and termed it as the Main Himalayan Thrust (MHT). The entire Himalayan chain is also the locale of substantial earthquake occurrences. During the past 200 years, the Himalayan arc has been struck by six great and several moderate earthquakes. Mapping of tectonic configuration and various thrusts geometry in the Himalayan region has been the focus of earth scientists. Magnetotelluric method has been used to map the crustal structure along a few transects in the Himalayan collision zone (Arora et al. 1982, 2007; Lemonnier et al. 1999; Gokarn et al. 2002).

Magnetotelluric investigations are carried out by Israil et al. (2008) in the Garhwal corridor along Roorkee to Gangotri (RKG) profile of the Uttarakhand Himalaya. Geoelctrical model presented earlier by Israil et al. (2008) shows the electrical image of crustal structure along the profile. However, geometry of thrust is difficult to draw from electrical features, which may be considered as lacunae of this model. The geoelectrical models obtained from the MT data along three profiles in central Himalaya was reviewed by Unsworth (2010). The aim of present investigations is:

(i) to study the electrical structure of the crust beneath the Indo-Gangetic Plains in the extended part of the profile by adding more data in the southern end of the old profile,

(ii) to improve data quality at earlier recorded noisy MT sites,

(iii) to update the earlier electrical model (Israil et al. 2008) of the crust by adding more data, robust processing and inversion, and

(iv) to compare electrical features of the two models (Israil et al. 2008 and updated model) and their relationship with the tectonic structure and seismicity.

Ten new MT sites have been added to the RKG profile of Israil et al. (2008). Out of which four MT sites are added to extend the profile about 20 $\mathrm{km}$ further south, and six noisy sites are repeated in the remote reference mode within this profile length. Thus, MT data from 37 sites (previous 27 and 10 new sites) are reprocessed by robust processing codes, and an updated average geoelectric strike and geoelectrical model are presented along the profile.

\section{Geology of Uttarakhand and description of the MT data}

Geologically, the Uttarakhand Himalayan region is divided into four concentric litho-tectonic domains, which are separated by three south verging thrusts (figure 1). Viewing from south to north, the Indo-Gangetic Plain (IGP) is the southernmost unit, which is separated from the Sub-Himalayan (SH) region by the Main Frontal Thrust (MFT) in the north and the peninsular shield towards south. It is essentially composed of vast alluvium deposits by the southerly-flowing river system from the Himalaya. These loose Pliocene-Recent sediments were laid over the Tertiary sediments and the Precambrian basement of the Indian Shield. The MFT, representing the youngest thrust zone, was activated during Pleistocene and demarcates the tectonic boundary between the IGP and Sub-Himalaya (Valdiya 2003). The Sub-Himalaya begins to the north of the MFT with an average elevation of $600 \mathrm{~m}$, and rises abruptly above the IGP along the MFT. The Sub-Himalaya predominantly consists of 5-6 km thick Tertiary and Quaternary sediments. The Lesser Himalayan (LH) domain, which follows on the north, has an average elevation of $2500 \mathrm{~m}$ with an increasing elevated profile towards the north. The LH domain largely consists of highly deformed Precambrian sedimentary rocks with stratified volcanics, and is considerably folded and fractured (Le Fort 1975). This domain is separated from the Sub-Himalaya by the north dipping Main Boundary Thrust (MBT), which hades northwards at $30^{\circ}-40^{\circ}$ (Khattri and Tyagi 1983; Khattri 1992). Next major thrust is the MCT in the north. In the study area, the MCT zone is bounded by the Munsiari Thrust (MT) in the south and Vaikrita Thrust (VT) in the north (Valdiya 1980; Gupta et al. 2012; Mahesh et al. 2013) The northernmost region of the profile is the Higher Himalayan $(\mathrm{HH})$ crystalline zone containing most of the famous peaks of the mountain range and has an average elevation of $4500 \mathrm{~m}$. The main tectonic elements of the Uttarakhand Himalayan region have an average strike of NW-SE (Khattri 1992).

MT data along the Roorkee-Gangotri (RKG) profile in the Garhwal Himalayan region was recorded in two phases. In the first phase, MT data from 27 sites were used to generate a 2D geoelectrical model of the crustal structure along the profile (Israil et al. 2008). Subsequently, in the second phase, $10 \mathrm{MT}$ sites are added to the profile during 2010-2012, out of which four sites extended the profile about $20 \mathrm{~km}$ in southern direction and six MT sites are added within the profile length (figure 1). In this paper we refer to the profile 


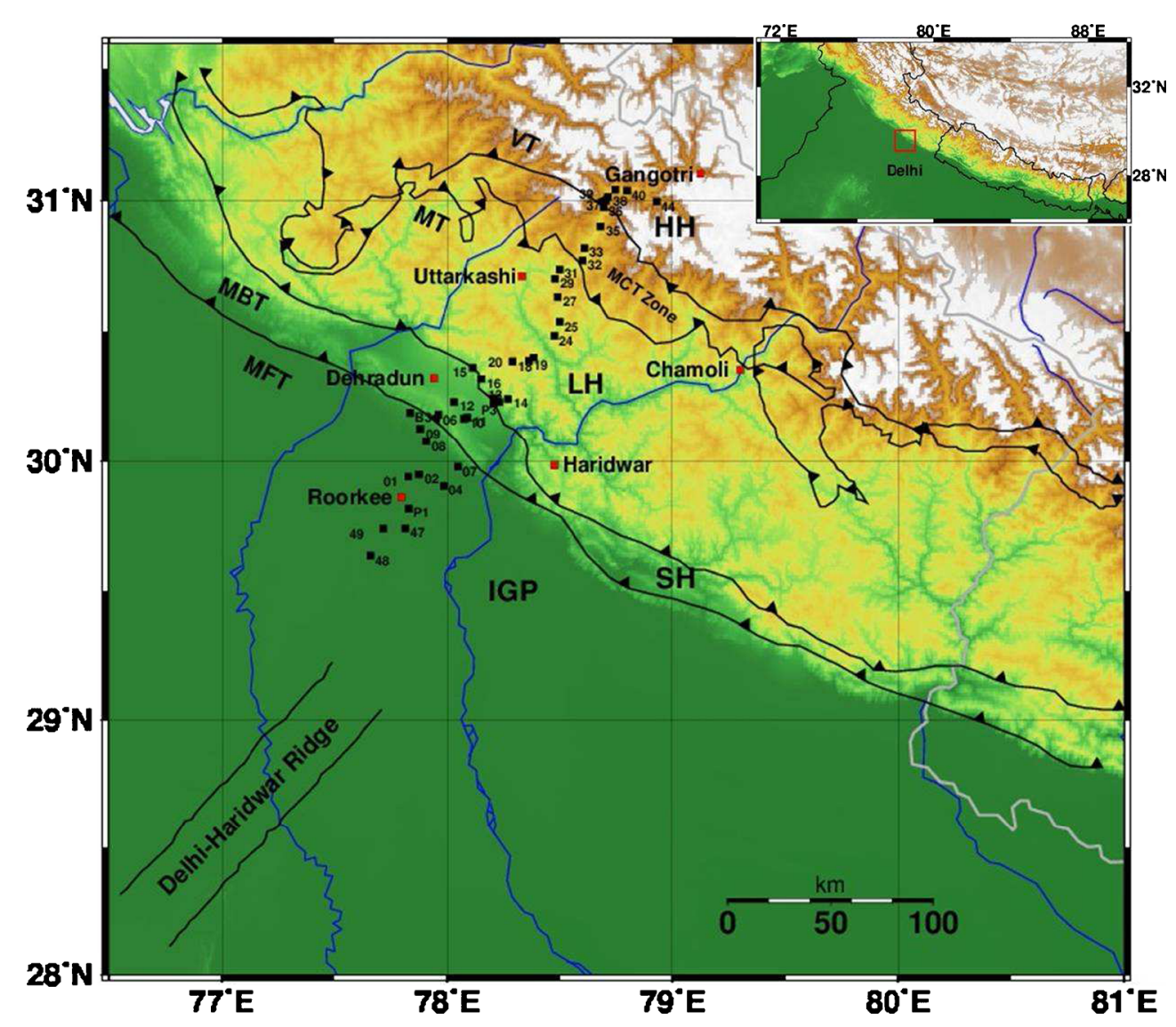

Figure 1. Simplified tectonic map of the study area, projected over topography, showing major Garhwal Himalayan thrusts: VT: Vaikrita thrust; MT: Munsiari thrust; MBT: Main Boundary thrust; MFT: Main Frontal thrust, IGP: Indo-Gangetic Plain, SH: Sub-Himalaya; LH: Lesser Himalaya, HH: Higher Himalaya (compiled from Valdiya 2003 and Mahesh et al. 2013). Magnetotelluric sites used in present study are shown by small squares with black background.

with 37 MT sites as extended Roorkee-Gangotri profile in the subsequent discussion. Details of the recording parameters are given in Israil et al. (2008). Recorded time domain data were transformed to the frequency domain impedance tensor using magnetotelluric processing code (MAPROS) (Friedrichs 2003). Subsequently, the entire dataset was reprocessed using robust noise-suppressing code (Smirnov 2003; Varentsov et al. 2003, 2005; Varentsov 2007). Thus, stable impedance tensor is estimated for 37 sites in the period range of $0.01-$ 2048 s. Computation of induction vectors requires a vertical magnetic field component, which was recorded by induction coil. We have used metronix induction coil which has dimension of $1.25 \mathrm{~m}$ length and $7.5 \mathrm{~cm}$ diameter. Vertical magnetic field $(\mathrm{Hz})$ coil was not buried fully at many MT sites due to hard Himalayan terrain and the estimated tipper values are noisy at those MT sites. As a result we could only obtain stable tipper responses at 26 sites.

Apparent resistivity and phase responses, representing all four litho-tectonic units - IGP, SH, LH, and MCT zone respectively, are shown in figure 2. Apparent resistivity responses in different lithotectonic units indicate complexity of geoelectric structure and dimensionality in the region. Phase responses at site nos. 38, 39, and 40 in the Higher Himalayan $(\mathrm{HH})$ region show $3 \mathrm{D}$ effects. Phases at these sites exceed $90^{\circ}$, and strong splitting of apparent resistivity in TE and TM modes are observed at these sites. Such responses are either associated with 3D electrical resistivity structure or electrical anisotropy (Weckmann et al. 2003; Weibke and Pous 2003). In the IGP, apparent resistivity in the TE and TM modes are overlapping at short period $(<20 \mathrm{~s})$, thus indicating the 1D electrical structure of the sediments in the IndoGangetic Plains. Splitting of apparent resistivity responses at long period in this region indicate the 2D regional electrical structure at deeper depth. Parallel shift in the apparent resistivity in TE and TM modes (site no. 13) is an example of static shift in the responses.

Real induction vectors in the Weise convention are shown in figure 3 along with the average strike direction, estimated at selected period. Figure 3 shows relationship of real induction vector with the strike direction and 3D behaviour of these vectors. Theoretically, in 2D structure, direction of the induction vector is perpendicular to the strike direction. However, direction and magnitude of real 


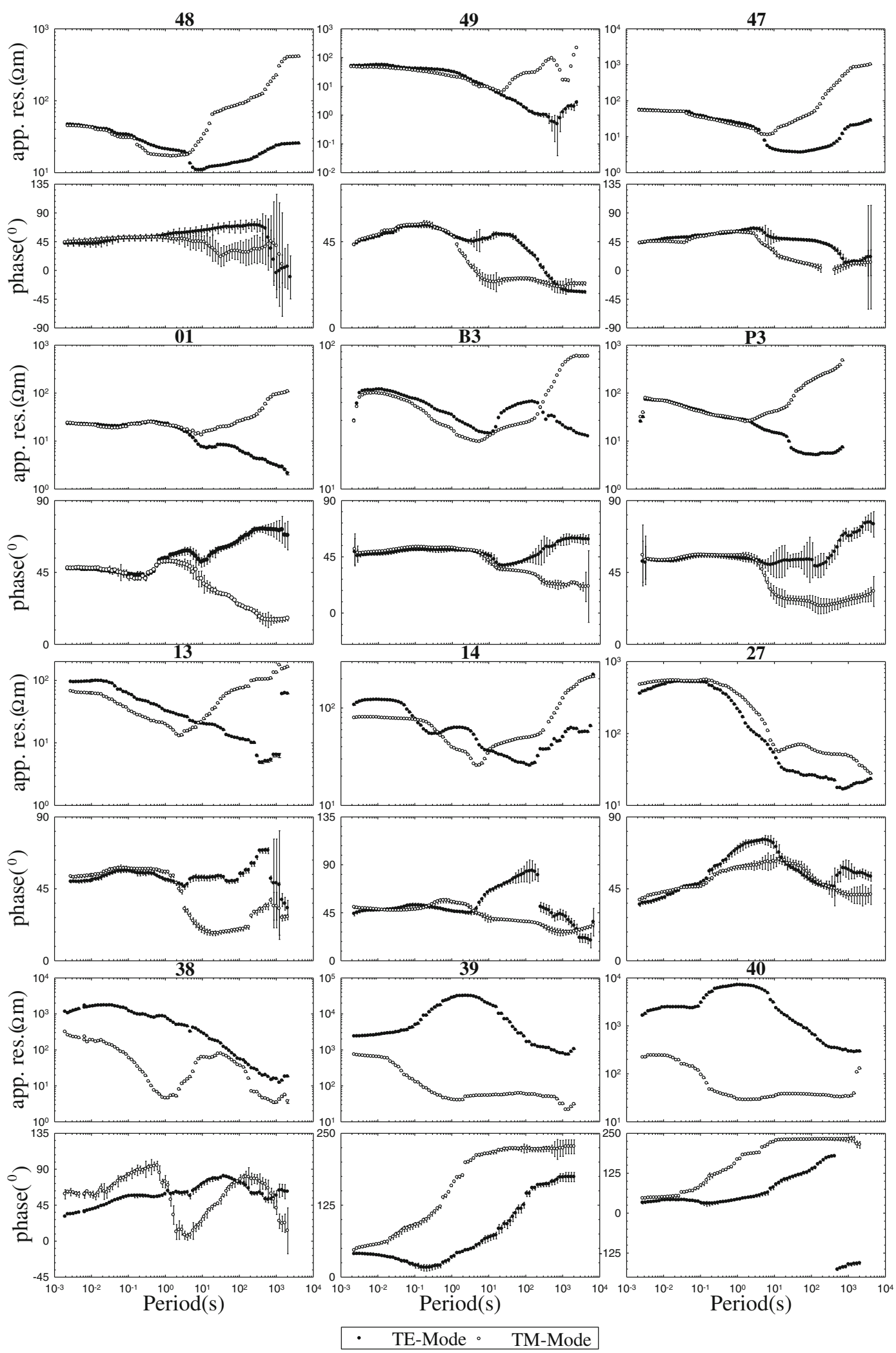

Figure 2. Observed apparent resistivity and phase curve for TE and TM-mode along the profile in four litho-tectonic units IGP, SH, LH, HH recorded at 12 representative MT sites. These sites include 10 new MT sites added in the present study.

induction vectors change. In a narrow belt over the conductor, real induction arrows align with the strike of the conductor (Adam 2002). In the IGP, it has been observed that the real induction vectors for short period $(<100 \mathrm{~s})$ are relatively unstable due to $1 \mathrm{D}$ nature of the IGP sediments, whereas 


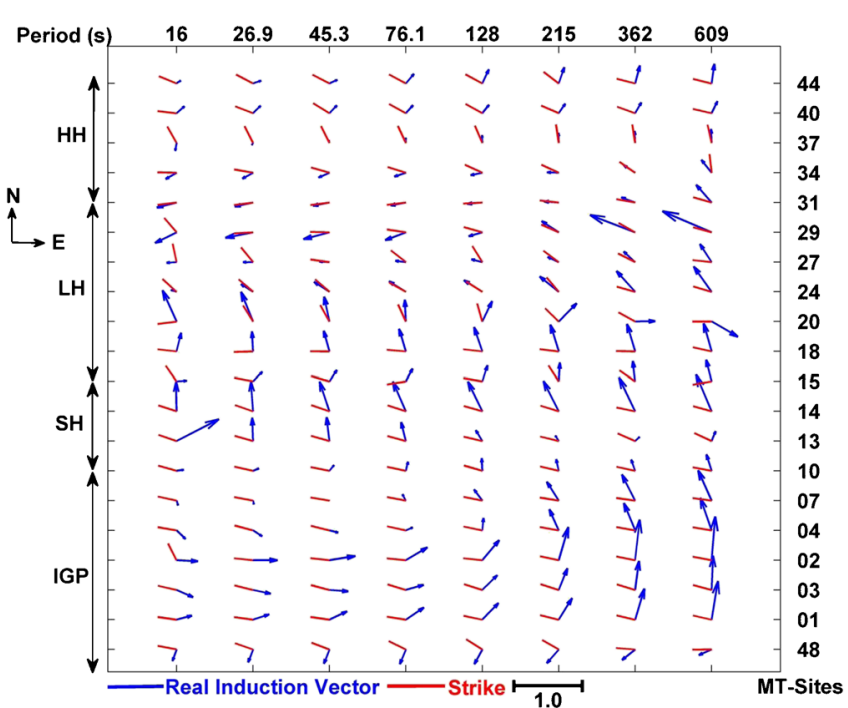

Figure 3. Real part of induction vectors (Weise convention) along with the average strike direction for 20 sites and eight different periods in each site. Four lithotectonic zones: Indo-Gangetic Plains (IGP), Sub-Himalaya (SH), Lesser Himalaya $(\mathrm{LH})$ and Higher Himalaya $(\mathrm{HH})$ regions and site numbers are shown along left and right vertical lines, respectively. Selected periods are shown along the top horizontal line.

these are nearly perpendicular to the strike for long period (>100 s).

Further north along the profile, magnitude of real induction vector reduces to the minimum at site nos. 10, 13, 27, 31, and 37. It suggests the presence of conductors beneath these sites. Near reversal in the direction of real induction vector is observed between site nos. 29 and 40. This suggests that a strong conductive zone exists between site nos. 29 and 40. Between sites 14 and 31 , induction vectors generally point towards northwest direction consistently indicating the possibility of some remote conductive zone to the east of the existing profile and regional 3D electrical structure. GDS studies (Arora and Mahashabde 1987) indicated the possibility of such a conductor.

\section{Estimation of geoelectric strike}

Initially, approximate strike directions are estimated as the direction of maximum absolute phase split orientation (MPSO) between the TE and TM mode impedance phase ( $\mathrm{Wu}$ et al. 2005). The MPSO is the simpler approach and may indicate strike direction for distortion free MT responses. As most of our MT responses have different degrees of distortions, more sophisticated decomposition schemes are used to parameterize distortion and to estimate average geoelectric strike direction. We have used three approaches: (i) GroomBailey (GB), (ii) Bahr's and (iii) Phase tensor decomposition to determine consistent average geoelectric strike direction. These methods determine geoelectric strike and quantify impedance distortion in terms of decomposition parameters. Groom and Bailey (1989) decomposition presents the observed impedance tensor $\left(Z_{\mathrm{obs}}\right)$ in terms of shear $(S)$ and twist $(T)$ angles as distortion parameters and the regional 2D impedance as follows:

$$
Z_{\mathrm{obs}}=R(\theta) T S Z_{2 D} R^{T}(\theta),
$$

$R(\theta)$ is a rotation matrix with angle $\theta$ as geoelectric strike direction. Physical basis of equation (1) is given by Groom and Bahr (1992). The distortion parameters twist $(T)$, shear $(S)$, the geoelectric strike, and the regional impedance tensor $\left(Z_{2 \mathrm{D}}\right)$ are estimated using a least square method by fitting the observed impedance tensor with the decomposition model. Limiting values of twist and shear are $\left|60^{\circ}\right|$ and $\left|45^{\circ}\right|$, respectively, which define validity of decomposition hypothesis. On the contrary, in Bahr $(1988,1991)$ approach the phase difference between the impedances of each column of the impedance matrix is minimized. The third approach, based on the phase tensor, gives the same strike as Bahr's decomposition for 2D structure (Caldwell et al. 2004). We have written MATLAB-based codes to implement all the three schemes. In validation test, we tested the accuracy of codes developed by our group with the corresponding results obtained through strike code (McNeice and Jones 2001). Table 1 shows geoelectric strike obtained from all the three methods, average strike, and distortion parameters - shear and twist. Geoelectric strike direction and real induction vector along the profile for selected periods are presented in figure 3 , which shows the relationship of real induction vector with the geoelectric strike direction and also indicates the area where real induction vectors are strongly influenced by remote conductors (Adam 2002). Figure 4 shows Bahr's phase sensitive skew (PSS) indicating that the responses are generally characterized as 2D (PSS $<0.3)$ except in a few localized zones for which PSS $>0.3$ represents the $3 \mathrm{D}$ nature. It was observed that in the IGP region, for short periods $(<1 \mathrm{~s})$, the strike direction is generally unstable and satisfies $1 \mathrm{D}$ criterion (maximum phase split in TE and TM-mode $<5^{\circ}$ ). Strike is also unstable for the zones which have a strong $3 \mathrm{D}$ effect. Phase responses at site nos. 38, 39, and 40 (figure 2) in the Higher Himalayan region exceeded $90^{\circ}$ indicating the 3D nature of geoelectric structure. Such responses are either associated with 3D electrical resistivity structure or electrical anisotropy (Weckmann et al. 2003; Weibke and Pous 2003).

In the period range $1-100 \mathrm{~s}$, the average strike directions are $\mathrm{N} 78^{\circ} \mathrm{W}, \mathrm{N} 70^{\circ} \mathrm{W}, \mathrm{N} 68^{\circ} \mathrm{W}$, and 
Table 1. Geoelectric strike estimated by three decomposition schemes-Groom-Bailey, Bahr's and phase tensor along with distortion parameters-shear and twist.

\begin{tabular}{llcccccc}
\hline & $\begin{array}{c}\text { Period } \\
\text { band }(\mathrm{s})\end{array}$ & $\begin{array}{c}\text { GB } \\
\text { strike }\left(^{\circ}\right)\end{array}$ & $\begin{array}{c}\text { BH } \\
\text { strike }\left(^{\circ}\right)\end{array}$ & $\begin{array}{c}\text { PT } \\
\text { strike }\left(^{\circ}\right)\end{array}$ & $\begin{array}{c}\text { Avg. } \\
\text { strike }\left(^{\circ}\right)\end{array}$ & Shear $\left(^{\circ}\right)$ & Twist $\left(^{\circ}\right)$ \\
\hline IGP & $1-100$ & 80 & 76 & 79 & 78 & 1.14 & 1.02 \\
& $100-1000$ & 77 & 77 & 80 & 78 & 6.71 & 1.89 \\
SH & $1-100$ & 73 & 69 & 68 & 70 & 0.92 & -0.32 \\
& $100-1000$ & 79 & 77 & 73 & 76 & 3.57 & 10.17 \\
LH & $1-100$ & 66 & 69 & 70 & 68 & 9.08 & 0.27 \\
& $100-1000$ & 73 & 72 & 84 & 76 & 14.06 & 5.79 \\
HH & $1-100$ & 83 & 76 & 84 & 81 & -4.71 & 9.74 \\
& $100-1000$ & 83 & 70 & 75 & 76 & -12.35 & -4.71 \\
\hline
\end{tabular}

IGP: Indo-Gangetic Plain; SH: Siwalik Himalaya; LH: Lesser Himalaya; HH: Higher Himalaya; GB: Groom-Bailey; BH: Bahr's; PT: Phase Tensor. All strike $\left(^{\circ}\right)$ are N $\left(^{\circ}\right) \mathrm{W}$.

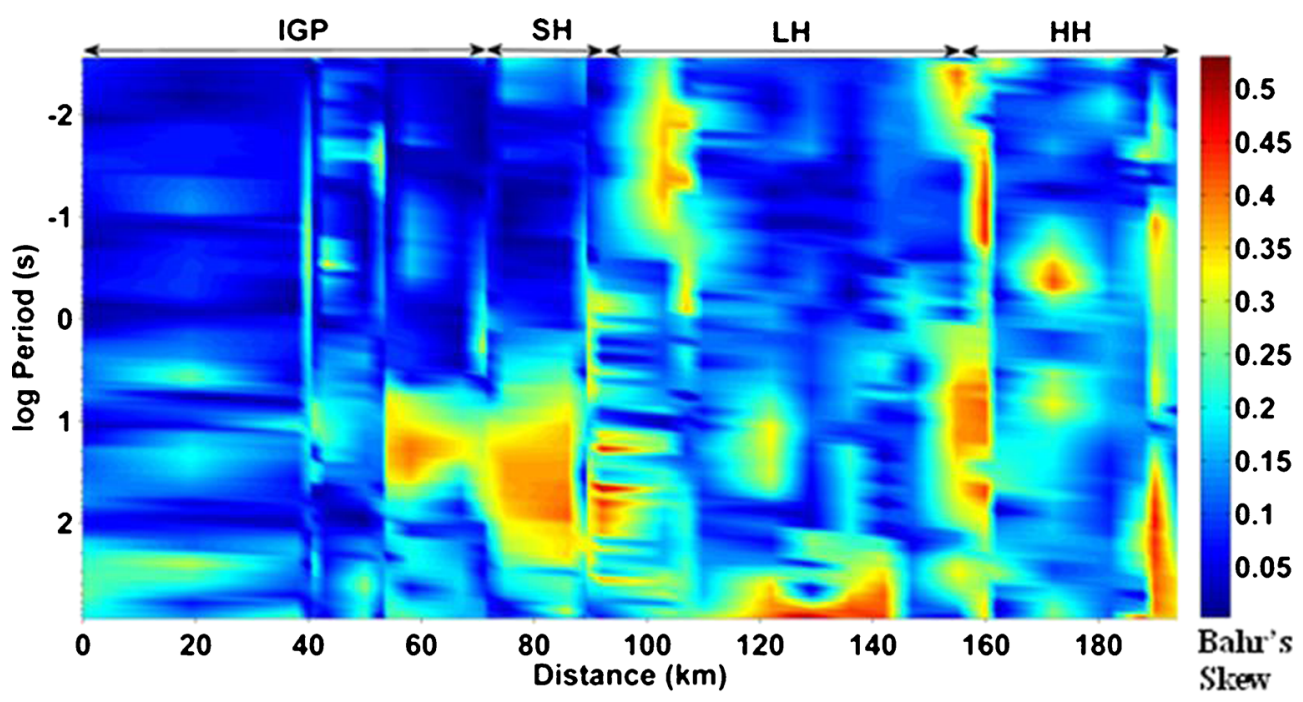

Figure 4. Pseudo-section showing the Bahr's phase sensitive skew representing the geoelectric dimensionality features along the profile in the four litho-tectonic zones: Indo-Gangetic Plane (IGP), Sub-Himalaya (SH), Lesser Himalaya (LH) and Higher Himalaya (HH).

$\mathrm{N} 81^{\circ} \mathrm{W}$ in four litho-tectonic zones (IGP, SH, LH, and $\mathrm{HH}$ ), respectively. The strike directions in the long period range (100-1000 s) are stabilized to $\mathrm{N} 77^{\circ} \mathrm{W}$ for all four litho-tectonic units along the profile, which has also been used for $2 \mathrm{D}$ inversion of the entire dataset.

\section{2D Inversion of MT data}

2D inversion finds the model whose response fits the observed data. The misfit between the observed apparent resistivity $\left(\rho^{\circ}\right)$ and phase $\left(\varphi^{o}\right)$ and the corresponding computed apparent resistivity $\left(\rho^{c}\right)$ and phase $\left(\varphi^{c}\right)$ is given by the estimated root mean square (rms) error, $\varepsilon$, and is defined as:

$$
\varepsilon=\sqrt{\frac{1}{2 N M} \sum_{j=1}^{M} \sum_{i=1}^{N}\left[\left(\frac{\rho_{i j}^{o}-\rho_{i j}^{c}}{e_{\rho i j}}\right)^{2}+\left(\frac{\psi_{i j}^{o}-\psi_{i j}^{c}}{e_{\psi i j}}\right)^{2}\right]} .
$$

Generally, the root mean square (RMS) misfit between 1 and 2 is an optimal choice. However, in the present case in some inversion runs, it exceeds 2 for noisy responses. Details of (i) selection of inversion parameters, (ii) different inversion runs, (iii) data selection and (iv) choosing initial model and sensitivity test are given in Israil et al. (2008). Interpretation profile is drawn according to the station's location. It has been observed through various inversion experiments that electrical nature of the final model is not sensitive to the minor changes $( \pm 10$ deg.) in the direction of the profile. The interpretational profile is designed at the azimuth of $\mathrm{N} 30^{\circ} \mathrm{E}$ with $\mathrm{X}=0$ at the southern end of the profile (site 48). Figure 5 shows elevation model in the upper diagram, while the lower figure shows the geoelectrical section along the profile, obtained by 2D inversion of MT data using Varentsov (2007) and Varentsov et al. (2010) code. Locations of the MT sites are indicated at the bottom and the major Himalayan thrusts are shown 


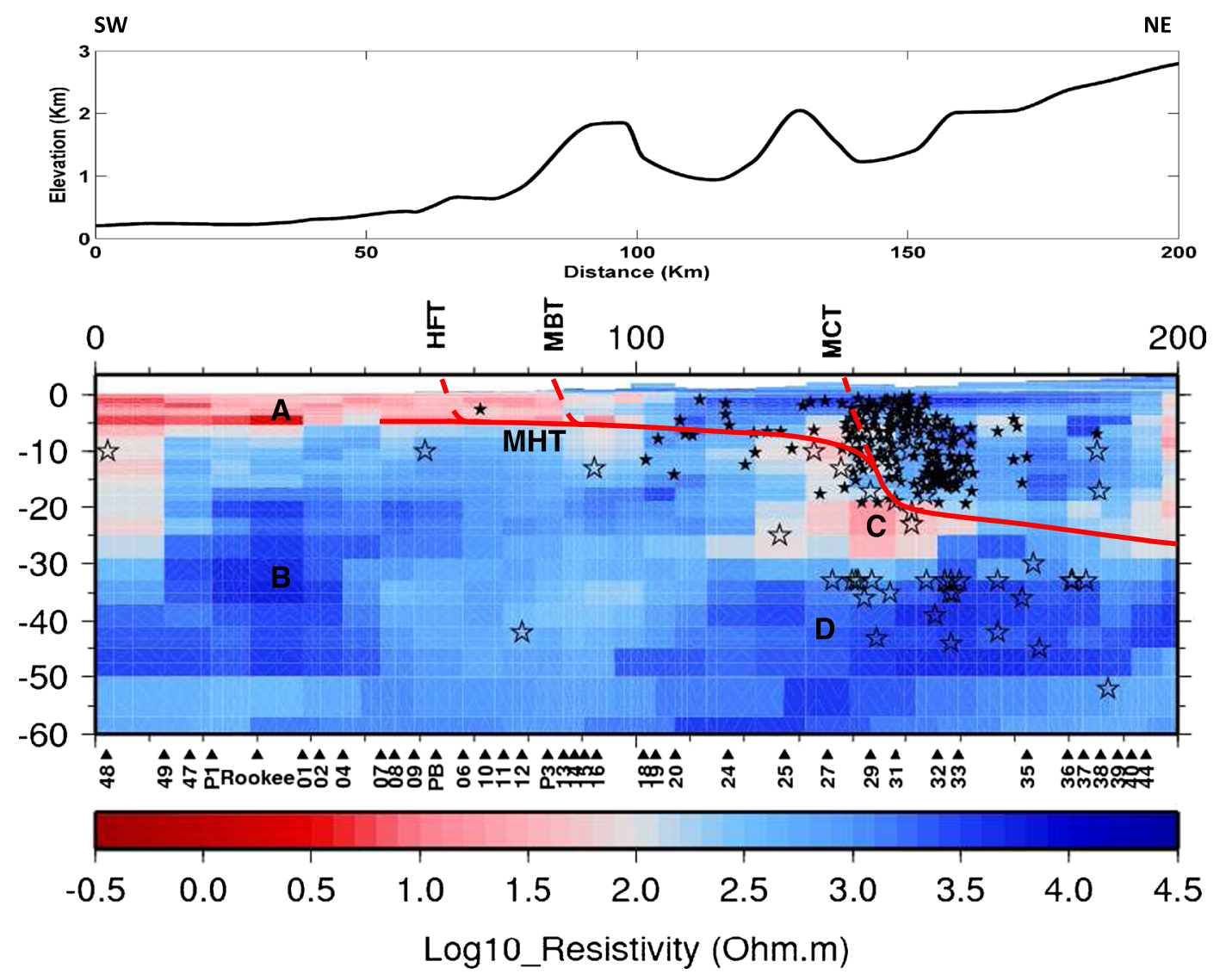

Figure 5. 2D resistivity-depth model for Roorkee-Gangotri profile with elevation profile in the upper figure, and 2D resistivity-depth model obtained from multi-component inversion of TE and TM responses in the lower figure. Also shown in this figure are: (i) the hypocenters of earthquake events projected in the model as 'open' and 'closed' stars with magnitude $>3$ and $<3$, respectively. (ii) Locations of MT sites indicated by filled triangles with site numbers on the bottom line of the model, and (iii) the interpretation and locations of major Himalayan thrusts (HFT, MBT, MCT, MHT).

in the cross-section. Further, the seismicity data from USGS records, Khattri (1992), Wason et al. (1999), and Mahesh et al. (2013) are projected on the geoelectric section. Pseudo-sections of the observed and calculated responses are shown in figure $6(\mathrm{a}-\mathrm{h})$ with RMS error of 1.2. The northern part of the profile between 100 and $200 \mathrm{~km}$ is showing poor fit and large error bar due to deviation from 2D assumption in this region, which cannot be fitted with $2 \mathrm{D}$ response. Figure $7(\mathrm{a}, \mathrm{b})$ shows data fit with the model responses along the profile at $1 \mathrm{~s}$ (figure 7a) and $181 \mathrm{~s}$ (figure $7 \mathrm{~b}$ ) periods respectively. Sensitivity test validated four major features in the model. Similarities and differences in the electrical features - A, B, C, and D of present model (called model (ii)), and corresponding features of the earlier model (called model (i); Israil et al. 2008) are discussed below.

\subsection{Feature- $A$}

Feature-A (figure 5) is a shallow conductive structure $(<50 \Omega \mathrm{m})$ mainly confined in the southern parts of the profile within the IGP and SH regions. Thickness of this feature appears to increase and reaches up to $7 \mathrm{~km}$ in the southern extended parts of the model, which is geologically reasonable within the IGP. The zone corresponds to the loose sediments of the Indo-Gangetic Plains, and Siwalik group of rocks of the Miocene and younger ages within the IGP and SH.

The shallow conductive zone extends from the first site in the southernmost end to site 18. The discontinuity appears to be associated with the tectonic thrust MBT. However, the HFT is not resolved in either of the two models. Geologically, the HFT separates loose sediments of the IndoGangetic Plains in the south from slightly consolidated Siwalik sediments in the north. Therefore, expected electrical resistivity contrast on either side of the HFT is not significant to be resolved by the MT data, used in the present study. The resistive zone below these conducting sediments is interpreted as the top of the Indian Plate. The detachment MHT is shown by gently-inclined line in the model (ii), while its geometry was difficult to draw in model (i). 
(a)

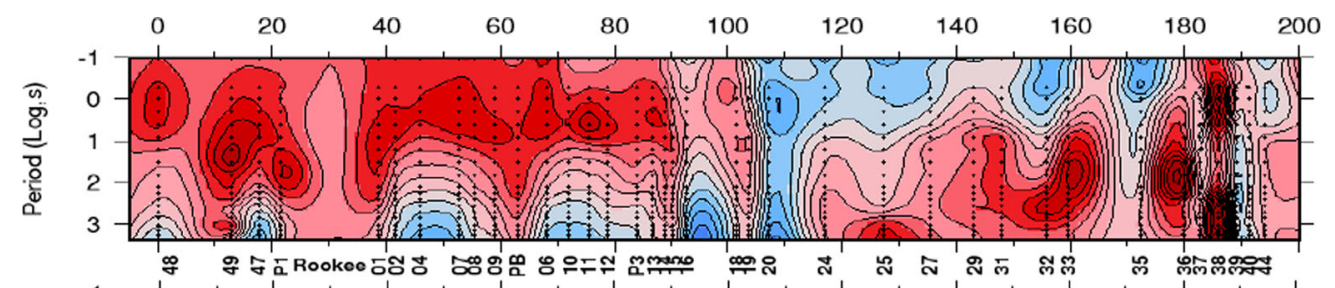

(b) TE Rho

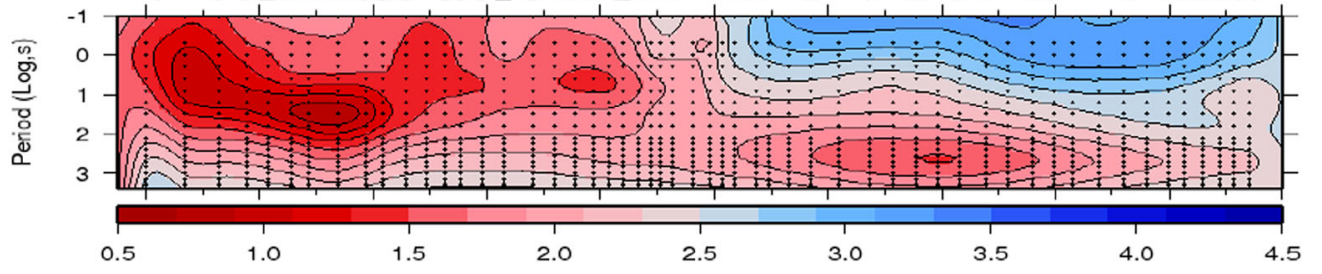

(c)

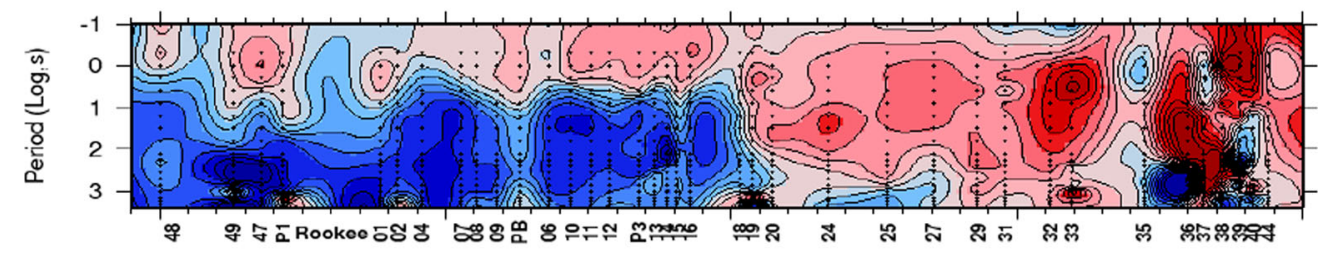

(d)TE Rhase

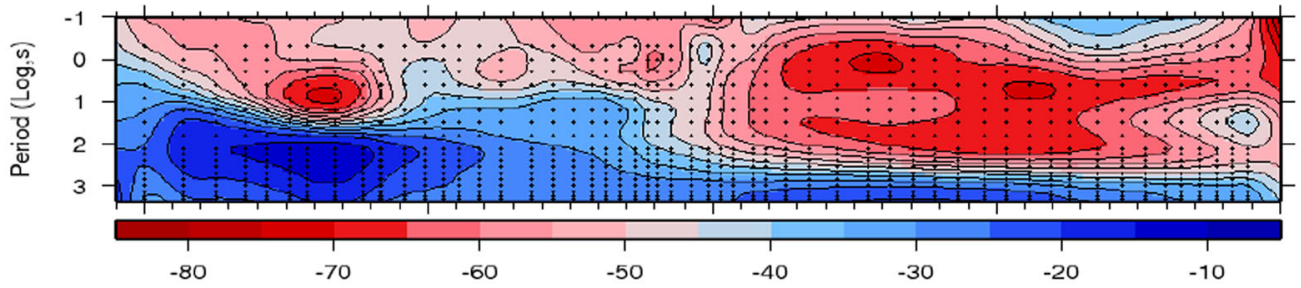

(e)

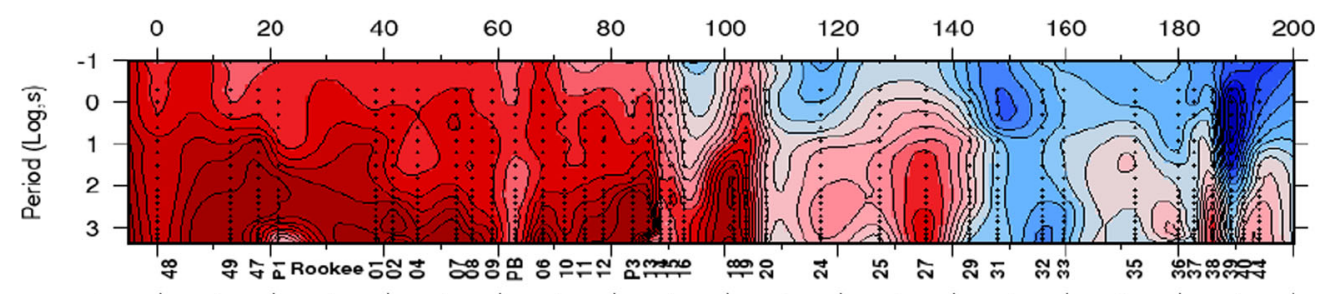

(f) TMRho

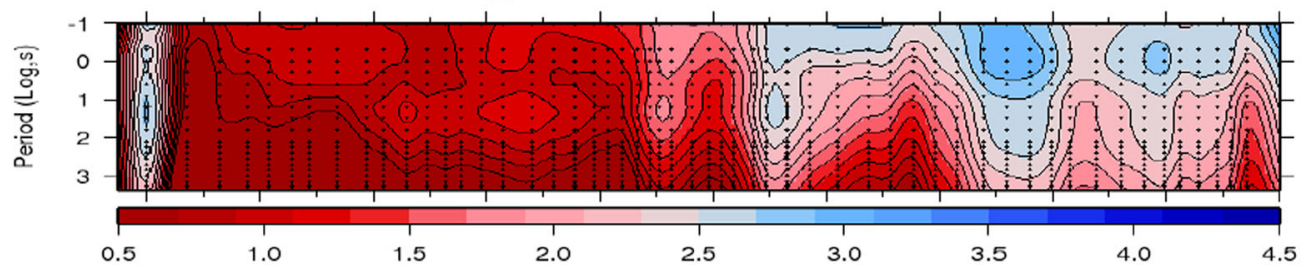

(g)

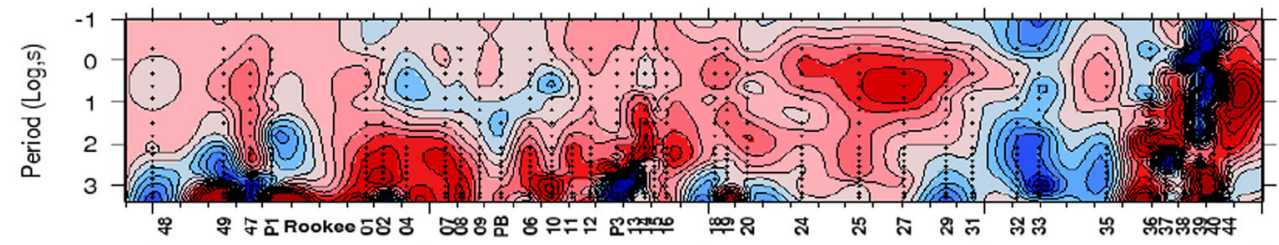

(h) TMPhase

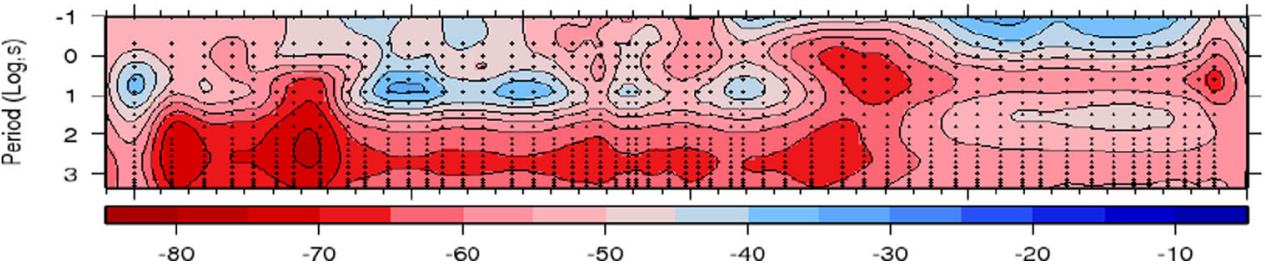

Figure 6. Pseudo-section plots for TE-mode: (a) observed apparent resistivity, (b) calculated apparent resistivity, (c) observed phase, and (d) calculated phase; TM-mode: (e) observed apparent resistivity, (f) calculated apparent resistivity, (g) observed phase and (h) calculated phase respectively. 

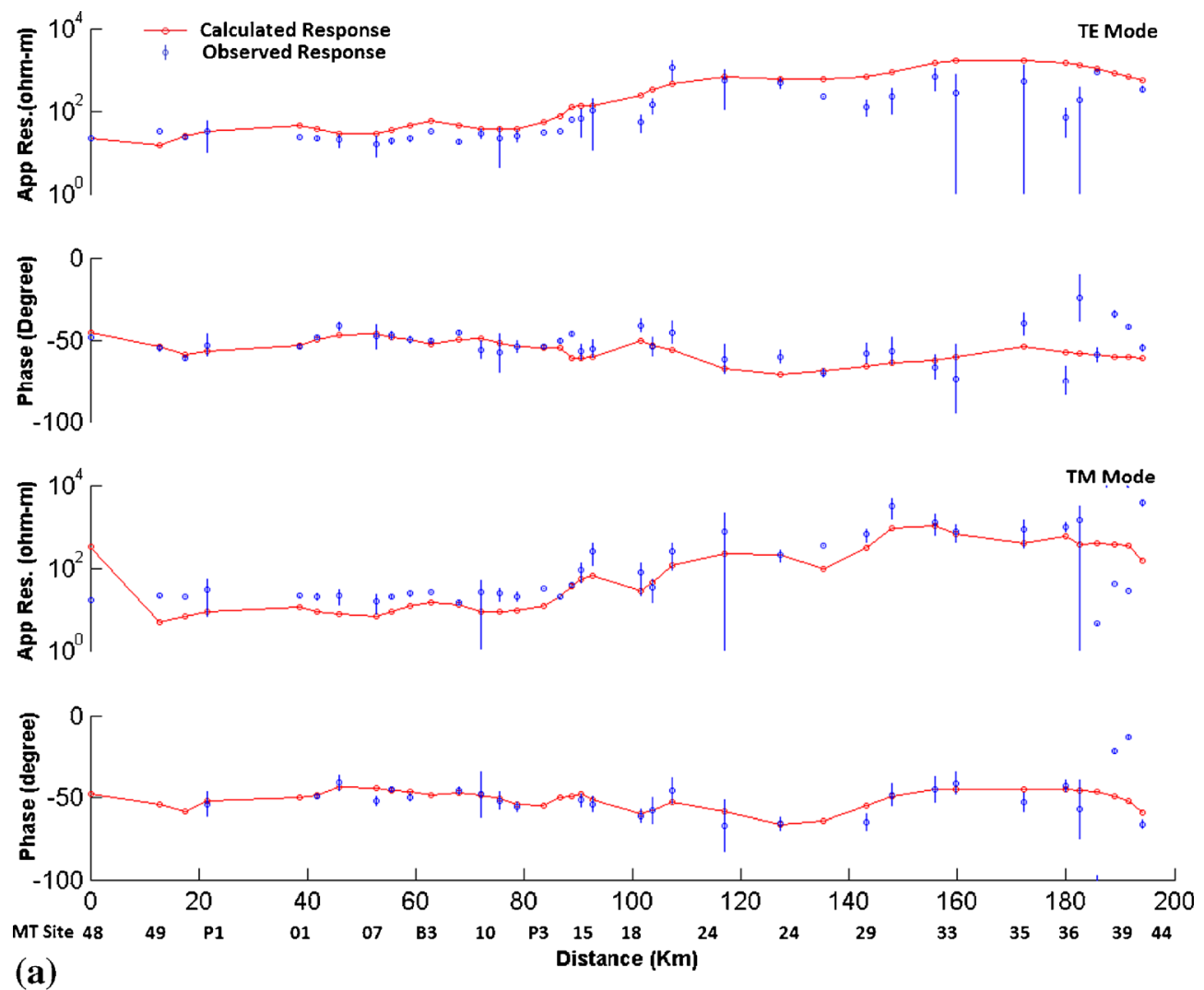

(a)
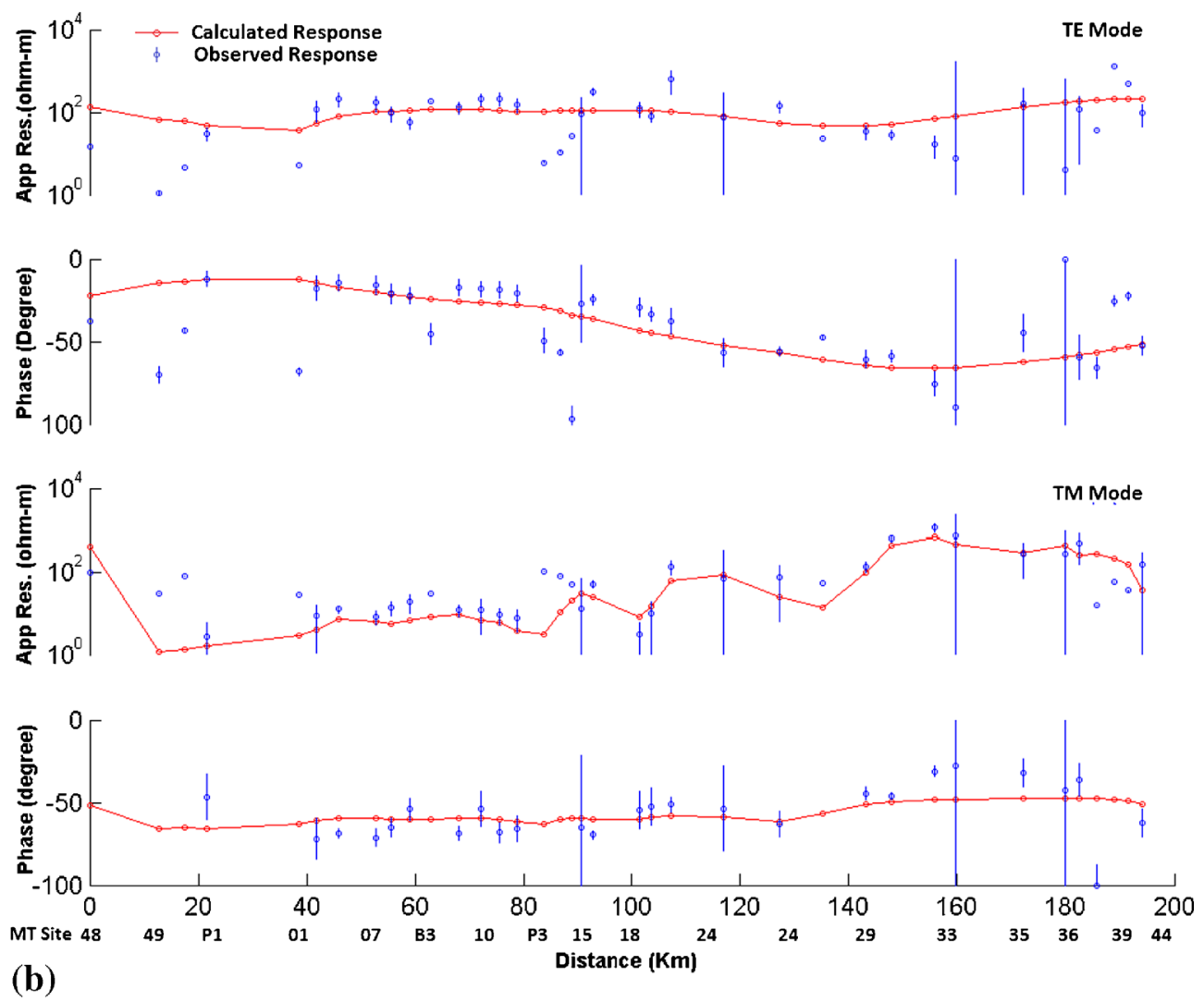

Figure 7. Fitting of observed and calculated responses along the profile at period of (a) $1 \mathrm{~s}$ and (b) $181 \mathrm{~s}$. 


\subsection{Feature- $B$}

Feature-B (figure 5) is an electrically resistive $(1000 \Omega \mathrm{m})$ basement representing the high resistivity of the subducting Indian Plate. In model (ii), southernmost extended part shows a low resistivity zone, which may be associated with fluid saturated fractured zone. This is an additional extended zone in model (ii), and was absent in model (i). Resistivity range of this feature matches with the corresponding resistivity in model (i).

\subsection{Feature- $C$}

Feature-C (figure 5 ) is a low resistivity $(<10 \Omega \mathrm{m})$ feature delineated in both the models (i) and (ii), and is located beneath the MCT zone. This feature is a typical example of mid-crustal conductor invariably observed in the Himalayan region. However, geometry of this conducting zone differs slightly in the two models. In model (i), this is a continuous conducting zone extending in the depth range from 6 to $25 \mathrm{~km}$, which appears to coincide with the hypocenters of local earthquakes (Israil et al. 2008). On the other hand, this particular conductor extends to the depth of $30 \mathrm{~km}$ in model (ii). To see relationship of this zone with the seismicity, more recently recorded earthquake hypocenters (Mahesh et al. 2013) are added in figure 5. Additional earthquake data brought clustering of earthquake hypocenters towards the boundary of conductive-resistive zones. This conducting zone is interpreted as fluid-filled crustal rock (Israil et al. 2008). This zone may also be associated with geothermally anomalous zone having high temperatures, high heat flow, and hot springs in the MCT zone (GSI 1991; Israil et al. 2008). In old model (i) (Israil et al. 2008), the geometry of MHT could not be inferred from the electrical features and we may call this a lacuna of model (i). The addition of new data, improvement in the responses by reprocessing, and use of inversion methodology with 3D penalty reveals the geometry of the MHT through electrical features in present study (model (ii)). There could be many explanations to this geometry, but our most preferred and robust model is the 'flat-ramp-flat' geometry of the thrust, which gets established from the MT data, possibly for the first time in the country. Recently 'flat-ramp-flat' geometry of MHT in Garhwal Himalayan region has also been delineated by receiver function method (Caldwell et al. 2013). The model is also consistent with the similar MT studies, which suggest that hypocenters are located above the fluid-filled conducting zone in the crust (Gupta et al. 1996; Fuji et al. 1997, etc.). Alternatively, this low resistivity zone can also be interpreted as a partially molten layer. The most likely conductive phase is the fluid, since underthrusting of the Indian crust can ensure continuous recharge of the hanging wall by fluids released during dehydration reactions (Lemonnier et al. 1999). Model (ii) suggests the possible flat-ramp-flat geometry of the MHT. In thrust tectonics in any mountain range, geometry of the thrust is explained by this 'flat-ramp-flat' trajectory where a thrust is located along a nearly-horizontal layer for some distance but then climbs up the section to the next horizontal surface, like climbing the stair case. Hence, the name of 'flat-ramp-flat'. Geological description of this geometry is available in structural geology literature like Fossen (2010). Geological significance of 'flat-ramp-flat' geometry in Himalayan tectonics is explained by Srivastava and Mitra (1994). More recently 'flat-ramp-flat' geometry of MHT in Garhwal Himalayan region has been delineated by receiver function method (Caldwell et al. 2013). In the present paper we have presented 'flatramp-flat' geometry of the Main Himalayan Thrust (MHT) along the profile, possibly for the first time in the country, by the MT data.

\subsection{Feature-D}

Feature-D (figure 5) is an electrically resistive feature below $30 \mathrm{~km}$ and is also present in both the models (i) and (ii). This feature is interpreted as an electrical image of the subducting crustal part of the Indian Plate in both the models.

In summary, it is possible to draw tectonic surface of the MHT as subhorizontal flat up to the MCT, and a ramp and further nearly subhorizontal flat surface in the north (figure 5). The MHT geometry as shown in model (ii) justifies the clustering of the earthquake locations above the ramp and conducting fluid saturated fractured region in the MCT zone.

\section{Conclusions}

Ten new MT sites are added to the RKG profile with the estimation of stable geoelectric strike direction for the entire profile. Subsequently, 2D geoelectrical model, presented earlier for the Garhwal Himalayan corridor, is updated and extended towards the southern end of the profile with the addition of four new MT sites. The major electrical features of this model are compared with the corresponding features of the earlier model (Israil et al. 2008). Thickness of the top conducting sediments in the Indo-Gangetic Plains increases to $7 \mathrm{~km}$ in the southern extended part of the profile. The strong lateral electrical discontinuities are consistent with major Himalayan thrusts - the MBT and the MCT, though the HFT is not visible as an 
electrical discontinuity in the model. Mid-crustal conductive zone is delineated in the MCT region extending to the depth of $30 \mathrm{~km}$. Focus of the earthquakes are mainly concentrated in the resistive blocks above and below this conductor. Relationship of the conductive feature in the MCT zone with the focus of earthquakes is an updated feature of this model, which reveals the possibility of flat-ramp-flat geometry of the MHT.

\section{Acknowledgements}

Authors are thankful to Prof. Alan G Jones, for providing the strike code for impedance decomposition. The present investigations were carried out with financial support from the Department of Science and Technology, Govt. of India. Authors are also thankful to Prof. A K Jain for the constructive suggestions with useful geological inputs to improve the quality of paper. The authors are all participants in the DST-RFBR Project, in which Dr Iv M Varentsov provided the 2D inversion code, and Dr M Yu Smirnov guided in data processing. Mr Paramjeet Mamoriya's help in various stages of revision is thankfully acknowledged. Authors are thankful to the two reviewers for their constructive suggestions to improve the paper.

\section{References}

Adam A 2002 Remote effects in real induction arrows; Ann. Geophys. 45(5) 699-701.

Arora B R and Mahashabde M V 1987 A transverse conductive structure in the northwest Himalaya; Phys. Earth Planet. Interiors 45 119-127.

Arora B R, Lilley F E M, Sloane M N, Singh B P, Srivastava B J and Prasad S N 1982 Geomagnetic induction and conductive structures in northwest India; Geophys. J. Roy. Astron. Soc. 69 459-475.

Arora B R, Unsworth M J and Rawat G 2007 Deep resistivity structure of the north-west Indian Himalaya and its tectonic implications; Geophys. Res. Lett. 34 L04307.

Bahr K 1988 Interpretation of the magnetotelluric impedance tensor: Regional induction and local telluric distortion; J. Geophys. 62 119-127.

Bahr K 1991 Geological noise in magnetotelluric data: A classification of distortion types; Phys. Earth Planet. Interiors 66 24-38.

Caldwell T G, Bibby H M and Brown C 2004 The magnetotelluric phase tensor; Geophys. J. Int. 158 457-469.

Caldwell W B, Klemperer Simon L, Lawrence J F, Rai S S and Ashish 2013 Characterizing the main Himalayan Thrust in the Garhwal Himalaya, India with receiver function CCP stacking; Earth Planet. Sci. Lett. 367 $15-27$.

Fossen H 2010 Structural Geology; Cambridge University Press, 463p.

Friedrichs B 2003 MAPROS: Magnetotelluric data processing software; Metronix GmbH; Braunschweig, Germany.

Fuji-ta Ogawa Y, Yamaguchi S and Yaskawa 1997 Magnetotelluric imaging of the SW Japan forearc - a lost paleoland revealed; Phys. Earth Planet. Interiors 102 231-238.

Gokarn S G, Rao C K and Gupta G 2002 Crustal structure in the Siwalik Himalayas using magnetotellucric studies; Earth Planets Space 54 19-30.

Groom R W and Bailey R C 1989 Decomposition of magnetotelluric impedance tensors in the presence of local three-dimensional galvanic distortion; J. Geophys. Res. 94 1913-1925.

Groom R W and Bahr K 1992 Correction for near surface effects: Decomposition of the magnetotelluric impedance tensor and scaling corrections for regional resistivities: A tutorial; Surv. Geophys. 13 341-379.

GSI 1991 Geothermal Atlas of India; Geol. Surv. India Spec. Publ. 19143.

Gupta H K, Sarma S V S, Harinarayana T and Virupakshi G 1996 Fluids below the hypocentral region of Latur Earthquake, India; Geophys. Res. Lett. 20(13) 15691572 .

Gupta S, Mahesh P, Sivaram K and Rai S S 2012 Active fault beneath the Tehri dam, Garhwal Himalaya - seismological evidence; Curr. Sci. 103(11) 1343-1347.

Israil M, Tyagi D K, Gupta P K and Niwas S 2008 Magnetotelluric investigations for imaging electrical structure of Garhwal Himalayan corridor, Uttarakhand, India; J. Earth Syst. Sci. 117 189-200.

Khattri K N 1992 Local seismic investigations in the Garhwal-Kumaun Himalaya; Geol. Soc. India Memoir 23 45-66.

Khattri K N and Tyagi A K 1983 Seismicity pattern in the Himalayan plate boundary and identification of the areas of high seismic potential; Tectonophys. 96 281-297.

Le Fort P 1975 Himalaya: The collided range. Present knowledge of the continental arc; Am. J. Sci. 275 7-44.

Lemonnier C, Marquis G, Perrier F, Avouac J P, Chitrakar G, Kafle B, Sapkota S, Gautam U, Tiwari D and Bano M 1999 Electrical structure of the Himalaya of central Nepal: High conductivity around the mid-crustal ramp along the MHT; Geophys. Res. Lett. 26 3261-3264.

Mahesh P, Rai S S, Sivaram K, Paul A, Sandeep Gupta, Sarma R and Gaur V K 2013 One dimensional reference velocity model and precise locations of earthquake hypocenters in the Kumaon-Garhwal Himalaya; Bull. Seismol. Soc. Am. 103(1) 328-339, doi: 10.1785/0120110328.

McNeice G W and Jones A G 2001 Multisite, multifrequency tenser decomposition of magnetotelluric data; Geophysics 66 158-173.

Molnar P 1990 A review of the seismicity and the rate of active underthrusting and deformation at the Himalaya; J. Him. Geol. 1(2) 131-154.

Seeber L, Armbruster J and Quittmeyer R C 1981 Seismicity and continental subduction in the Himalayan arc; In: Zagros-Hindukush-Himalaya Geodynamic Evolution (eds) Gupta H and Delany F, Am. Geophys. Union, Geodyn. Ser. 3 215-242.

Smirnov M Yu 2003 Magnetotelluric data processing with a robust statistical procedure having a high breakdown point; Geophys. J. Int. 152 1-7.

Srivastava Praveen and Mitra Gautam 1994 Thrust geometries and deep structure of the outer and Lesser Himalaya, Kumaon and Garhwal (India): Implication for evolution of the Himalayan fold-and-thrust belt; Tectonics 13(1) 89-109.

Unsworth M 2010 Magnetotelluric studies of active continent-continent collisions; Surv. Geophys. 31 137161.

Valdiya K S 1980 Geology of the Kamaun Lesser Himalaya; Wadia Institute of Himalayan Geology, Dehradun, 291p. 
Valdiya K S 2003 Reactivation of Himalayan Frontal Fault; Curr. Sci. 85 1031-1040.

Varentsov Iv M 2007 Joint robust inversion of magnetotelluric and magnetovariational data. Electromagnetic sounding of the Earth's interior; In: Methods in Geochemistry and Geophysics (ed.) Spichak V V, Elsevier, pp. 189-222.

Varentsov Iv M, Sokolova E Yu, Martanus E R, Nalivaiko K V and BEAR W G 2003 System of EM field transfer operators for the BEAR array of simultaneous soundings: Methods and results; Izvestya Phys. Solid Earth 39(2) $118-148$.

Varentsov Iv M, Sokolova E Yu and EMTESZ Working Group 2005 The magnetic control approach for the reliable estimation of transfer functions in the EMTESZ Pomerania Project; Publ. Inst. Geophys. Pol. Acad. Sci. C95(386) 68-79.

Varentsov Iv M, Bai D and Sokolova E Yu 2010 Joint inversion of long-period $\mathrm{MT} / \mathrm{MV}$ data at EHS3D transects
(Eastern Tibet). $20^{\text {th }}$ Workshop on EM induction in the Earth (Extended Abstract), Egypt Giza S7-05 4P.

Wason H R, Kumar J and Walia S K 1999 Local seismicity of the Garhwal Himalaya subsequent to the Uttarkashi earthquake of October 20, 1991; Gondwana Res. Group Memoir 6 335-340.

Weckmann U, Ritter O and Haak V 2003 A magnetotelluric study of the Damara Belt in Namibia 2. MT phase over $90^{\circ}$ reveal the internal sltructure of the Waterberg Fault/Omaruru Lineament; Phys. Earth Planet. Interiors 138 91-112.

Weibke H and Pous J 2003 Anomalous phases exceeding $90^{\circ}$ in magnetotellurics: Anisotropic model studies and a field example; Geophys. J. Int. 155 308318.

Wu X, Ferguson I J and Jones A G 2005 Geoelectric structure of the Proterozoic Wopmay Orogen and adjacent terranes, Northwest Territories, Canada; Canadian J. Earth Sci. 42 955-981. 